\title{
Epiregulin can effectively mature isolated cumulus-oocyte complexes, but fails as a substitute for the hCG/epidermal growth factor stimulus on cultured follicles
}

\author{
Sergio Romero and Johan Smitz \\ Follicle Biology Laboratory (FOBI), Vrije Universiteit Brussel (VUB), UZ Brussel, Laarbeeklaan 101, Brussels 1090, \\ Belgium
}

Correspondence should be addressed to S Romero; Email: sromerol@vub.ac.be

\begin{abstract}
Epiregulin mediates LH ovulatory effects in vitro. This study evaluated the use of epiregulin as an alternative to hCG/epidermal growth factor (EGF) stimulus upon cultured ovarian follicles in contrast to isolated cumulus-oocyte complexes (COCs). Pre-antral mouse ovarian follicles were cultured for 12 days and final maturation was induced by administration of $0.65 \mathrm{nM}$ EGF or $100 \mathrm{nM}$ epiregulin without or with $1.2 \mathrm{IU} / \mathrm{ml}$ hCG. Results showed that both EGF or epiregulin as sole stimulators are poor inducers of mucification/expansion of cumulus cells and oocyte meiotic reinitiation in follicle-enclosed COCs (25 \pm 17 and $22 \pm 16 \%$ GVBD respectively; versus $97 \pm 4$ and $90 \pm 15 \%$ GVBD by control hCG/EGF and hCG/epiregulin respectively; mean \pm s.D). Furthermore, EGF or epiregulin did not induce follicle luteinisation: progesterone production was marginally increased and oestradiol was incompletely shut down. Supposing that the sub-normal progesterone secretion was a potential cause for incomplete meiosis in this model, effectiveness of progesterone supplementation and addition of a progesterone receptor inhibitor (RU486) were evaluated on meiotic resumption. Progesterone was not found to be a major regulator of meiosis in this mouse model. Epiregulin induced meiosis more effectively in COCs isolated from cultured preovulatory follicles in a secondary culture well. In conclusion, epiregulin has similar effects as EGF upon fully grown follicles. Used as a sole stimulator of periovulatory events in intact cultured follicles, both are poor inducers of follicle luteinisation and oocyte maturation. By contrast, epiregulin is as efficient as hCG/EGF, when used as meiotic stimulator for COCs isolated from the follicular environment (mural granulosa and theca cells; and conditioned medium).

Reproduction (2009) 137 997-1005
\end{abstract}

\section{Introduction}

Ovulation is a complex process by which large antral ovarian follicles respond to the rise of $\mathrm{LH}$, inducing transcription of several genes in mural granulosa and theca cells that express the $\mathrm{LH}$ receptor. As an immediate reaction to the effects on theca and granulosa cells, the cumulus-corona cells undergo expansion and secrete hyaluronic acid in the intercellular space (mucification) and the oocyte resumes meiosis.

Recent data have demonstrated that epidermal growth factor (EGF)-like factors are important effectors of $\mathrm{LH}$ action on the follicle wall-inducing oocyte maturation (Park et al. 2004, Ashkenazi et al. 2005). Several follicle culture systems have been developed as models for assisted reproduction. These systems have shown that oocyte cytoplasmic/nuclear maturation can be achieved in vitro to some degree, but that developmental competence is still far from what can be produced per ovulated oocytes in vivo (for a review, Eppig 1994, Cortvrindt \& Smitz 2002). Especially for in vitro maturation (IVM) practice, where immature cumulus-oocyte complexes
(COCs) are retrieved from smaller follicles, it might be useful to supplement medium with positive triggers that have their receptor on the cumulus cells.

EGF-like factors: epiregulin (EREG); beta-cellulin (BTC); and amphiregulin (AREG), were shown to be upregulated in mural granulosa cells of pre-ovulatory follicles, 3-4 h after the LH ovulatory stimulus (Park et al. 2004, Ashkenazi et al. 2005). Furthermore, Sekiguchi et al. (2004) reported that EREG and AREG were already present in granulosa cells $24 \mathrm{~h}$ after pregnant mare serum gonadotropin (PMSG) injection in rats. Among the EGFlike factors, EREG was shown to induce the highest meiotic resumption response at lowest concentrations (compared with AREG and BTC; Ashkenazi et al. 2005). It has been demonstrated that also AREG is able to induce expression of genes related to mucification and expansion of cumulus cells (Ptgs2, Has2 and Tnfaip6) and to steroidogenesis (Star and Cyp11A1). Prostaglandins such as PGE2 have a positive feedback on the expression of EGF-like factors in the periovulatory follicle through the prostaglandin receptor (Shimada et al. 2006). 
In in vitro follicle culture systems (mouse), the role of EGF on steroidogenesis in the growing and ovulatory follicle has been discussed before. Almahbobi et al. (1995) reported that EGF or TGFA block antral follicle growth in vitro and reduce oestradiol $\left(\mathrm{E}_{2}\right)$ production, compared with the control. Smitz et al. (1998) reported that when used as an ovulatory stimulus in cultured mouse follicles, EGF could induce meiotic reinitiation; however, the ensuing production of progesterone by luteinising follicles was minimal, suggesting that progesterone production and oocyte meiotic maturation could be independent events. Nevertheless, Jamnongjit et al. (2005) showed that EGF induced progesterone production in COCs, and additionally, they showed that progesterone as well as testosterone was able to induce oocyte meiotic resumption.

In addition to the long known history of progesterone as a meiotic stimulus in Xenopus laevis (Sadler \& Maller 1981), Borman et al. (2004) showed that in non-human primates progesterone can promote oocyte nuclear maturation after controlled ovarian stimulation. However, without hCG, progesterone fails to elicit ovulation in large pre-ovulatory follicles. In mammals, progesterone is almost exclusively produced by mural cells upon the ovulatory stimulus (Li et al. 2000), and it seems to be more related to the ovulatory process rather than to oocyte maturation. This was further substantiated by experiments showing that follicles in knockout mice for progesterone receptor (PRKO mice) cannot rupture, presumably as a result of the low expression of matrix metalloproteinase Adamts 1 and cathepsin L (Espey et al. 2000, Robker et al. 2000a, 2000b).

In the frame of studies with cultured COCs and intact follicles, our hypothesis was that epiregulin could be used as a sole stimulator of nuclear maturation, cumulus mucification/expansion and follicle luteinisation (progesterone production). The purpose was to evaluate actions of epiregulin in comparison with those of EGF or the standard hCG/EGF stimulus on cultured intact follicles and on isolated COCs.

\section{Results}

\section{Follicle response to EGF and EREG}

\section{Cumulus cell mucification}

Efficacy of EGF and EREG for inducing mucification of cumulus cells, oocyte meiotic resumption and follicle luteinisation on 12-days-cultured follicles was assessed. Mucification and expansion of cumulus cells happened for all groups; however, mucification/expansion induced either by EGF or EREG was more restricted to the outer layers of cumulus cells, while the inner layers were neither mucified nor expanded. Figure $1 \mathrm{~A}$ shows the morphological difference in expansion and mucification in cumulus cells from the control group, stimulated with $\mathrm{hCG} / \mathrm{EGF}$, and from the EREG-treated group.
In the next approach, the effect of hCG/EGF and EGF alone on the induction of mucification in the cumuluscorona cell layer was assessed by means of quantification of one of the mucification-related genes, hyaluronan synthase 2 (Has2), by real-time PCR. At $4 \mathrm{~h}$ after hCG/EGF stimulus, the levels of Has2 mRNA were significantly higher than levels before stimulus $(0 \mathrm{~h})$ and also significantly higher than in follicles treated either with 0.65 or $65 \mathrm{nM}$ EGF. Although the levels on Has2 mRNA rose in response to EGF stimulus, levels did not significantly differ from $0 \mathrm{~h}$ (Fig. 1B).

\section{Oocyte meiotic maturation}

Oocyte meiotic stages were scored $16 \mathrm{~h}$ after stimulation with hCG/EGF (control), hCG/EREG, EGF or EREG.

In the control group, hCG/EGF stimulus induced reinitiation of meiosis (GVBD + polar body (PB)) in $97 \%$ of the oocytes, $89 \%$ reaching $\mathrm{PB}$ stage; only $3 \%$ of the oocytes remained in germinal vesicle (GV) stage (Fig. 2). By contrast, EREG induced oocyte meiotic resumption in $21 \%$ of the stimulated follicles; $6 \%$ did not progress further than GVBD stage and PB extrusion was observed in $15 \%$ of all follicles, these results were comparable with 9\% GVBD and $16 \%$ PB respectively in the EGF-treated group.

Surprisingly, when comparing hCG/EREG treatment with hCG/EGF (control), it was noticed that although hCG/EREG induced meiotic resumption in $90 \%$ of the oocytes (97\% in control group); the PB extrusion was present in only $53 \%$ of the oocytes ( $89 \%$ in control).

\section{Assessment of steroid production by cultured follicles}

Steroids production profiles were compared, among the treatment groups, at the end of culture. In the control group (hCG/EGF), $E_{2}$ concentration decreased from day 12 to day 13, to values even lower than expected by dilution during medium replenishment on day 12 (when stimulation medium is added, concentration of steroids is diluted by a factor of 1.67). Meanwhile, progesterone production increased by $\sim 100$ times (Fig. $3 \mathrm{~A}$ and $\mathrm{B}$ ).

Under EGF and EREG stimuli, $E_{2}$ levels did not decrease and values were somewhat higher on day 13 than on day 12 (Fig. 3A); progesterone levels showed only a slight increase, by far lower $(P<0.001)$ than the increase obtained after hCG/EGF or hCG/EREG (Fig. 3B).

\section{Progesterone effects in follicle culture}

Since cultured follicles exposed to both EGF or EREG showed only a minor increase in progesterone, the question was addressed whether in this model deficient progesterone receptor activation could be the underlying cause of low maturation rates on oocytes, this was assessed in the two following experiments. 
A
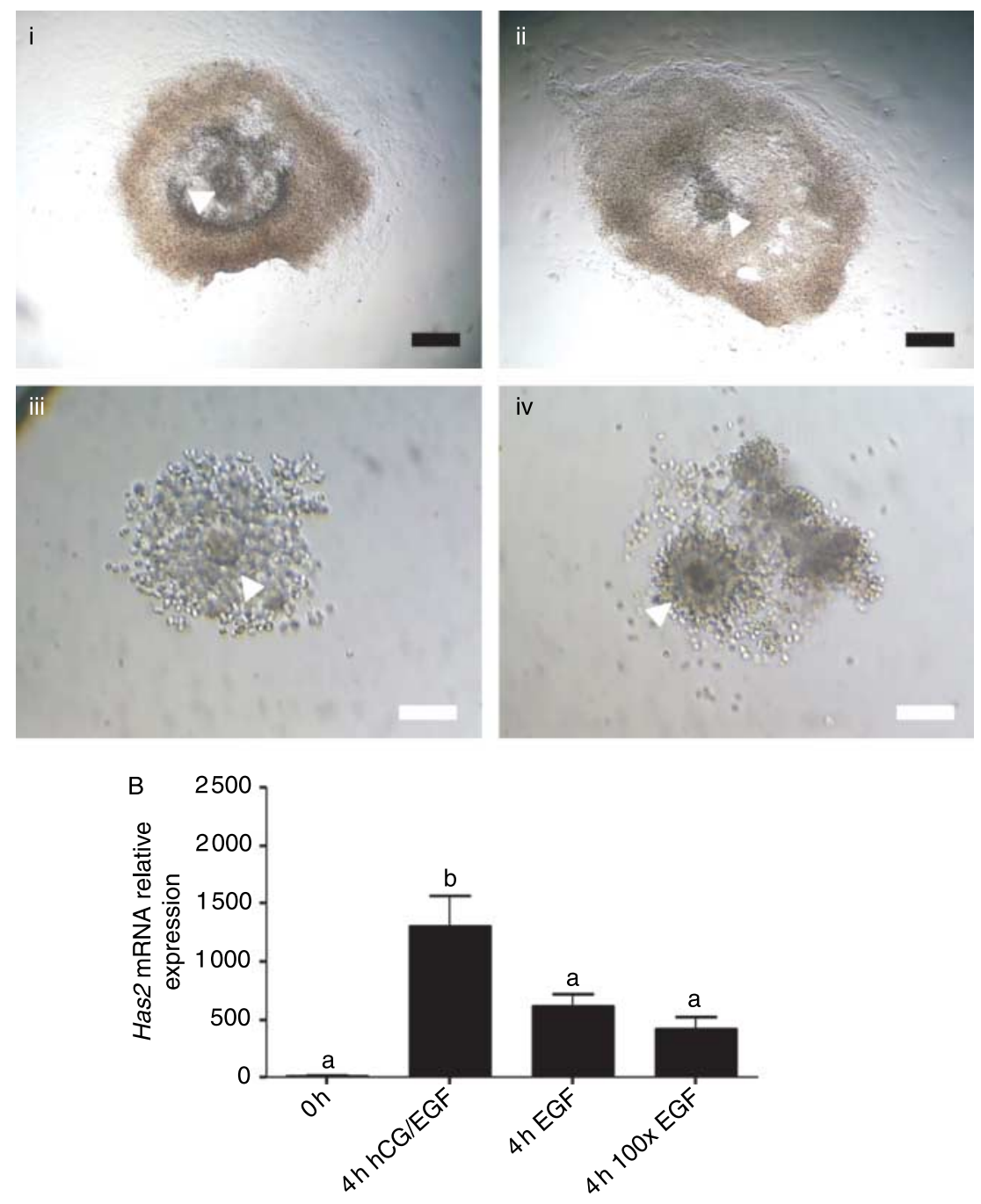

Progesterone receptor blockage by RU486

Potential effects of endogenously produced progesterone (after stimulus with hCG/EGF) were prohibited by the administration of a progesterone inhibitor, RU486 (10 and $100 \mu \mathrm{M})$. This inhibitor was added to the follicle culture immediately before stimulation with hCG/EGF. No differences in mucification or expansion were observed among the different treatments (data not shown).

Oocyte nuclear maturation, scored $16 \mathrm{~h}$ later, showed that in the control group, $98 \%$ of the oocytes resumed meiosis and the extruded PB was present in $86 \%$ of the oocytes. In the presence of RU486, PB rate was significantly lower, 62 and 56\%, for 10 and $100 \mu \mathrm{M}$ respectively (Fig. 4).

\section{Progesterone supplementation to epiregulin ovulatory stimulus}

Progesterone was added to culture medium together with EREG. In the control group, hCG/EGF induced
Figure 1 (A) Mucification of cumulus cells after hCG/EGF or EREG meiotic stimuli. Intact follicles $16 \mathrm{~h}$ after stimulation with hCG/EGF (i) or EREG (ii). Mucified COCs retrieved from follicles treated for $16 \mathrm{~h}$ with hCG/EGF (iii) or EREG (iv). Note complete mucification in (iii). White arrowheads point out mucification and expansion. Black scale bar $=250 \mu \mathrm{m}$; white scale bar $=100 \mu \mathrm{m}$. (B) Relative expression of mRNA for Has2 in cultured follicles after stimulation with $1.2 \mathrm{IU} / \mathrm{ml}$ hCG/0.65 nM EGF, 0.65 nM EGF (EGF) or 65 nM EGF $(100 \times E G F)$. Bars represent mean + s.E.M. Different letters state statistical significant difference among treatments $(P<0.05)$. full-oocyte meiotic resumption (100\%) and 91\% extruded the first PB. Progesterone alone did not induce either meiotic resumption or mucification/expansion of cumulus cells. Furthermore, addition of progesterone to EREG medium had no effect on either oocyte meiotic reinitiation or final PB rate compared with the EREG treatment alone (19 and 20\% meiotic reinitiation; 6 and $10 \%$ of PB rate respectively; Fig. 5).

\section{Epiregulin stimulation in isolated COCs from fully grown follicles}

In current clinical practise, IVM considers solely retrieved COCs, which are cultured for a short period in a freshly prepared medium. In this way, there is no influence of mural granulosa or theca cells, or by factors secreted by these cells into the media. Therefore, epiregulin's ability to induce meiotic resumption in fully grown oocytes was tested also on individual COCs. These COCs were 


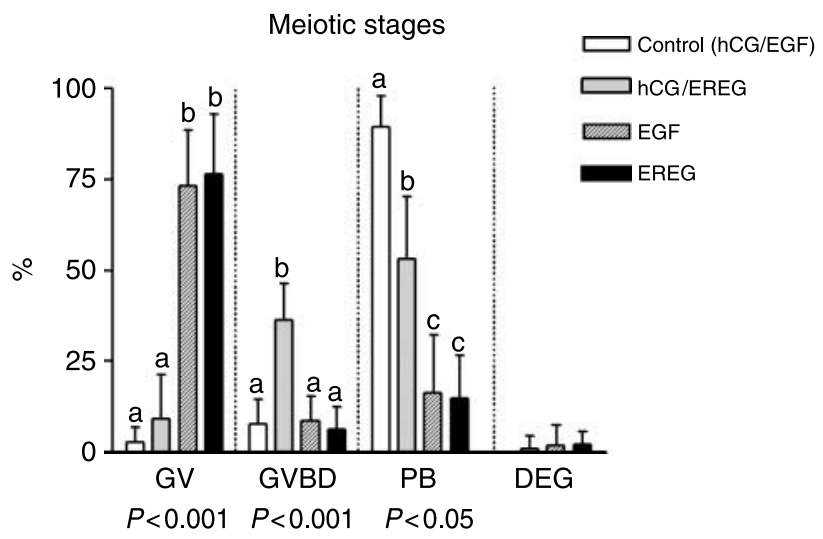

Figure 2 Meiotic stages after follicle stimulation with hCG/EGF, hCG/EREG, EGF or EREG. Results are expressed as mean percentage +S.D. of three independent experiments. Different letters state statistical significant difference among treatments. $n=9$ plates per treatment, obtained from three independent experiments.

isolated out of in vitro fully grown follicles and placed in a secondary well containing either fresh medium (FM) or conditioned medium $(\mathrm{CM}$; obtained by pooling spent medium from fully grown follicles). While placed in CM, a large proportion of complexes kept the association between cumulus cells and the oocyte; and consequently $16 \mathrm{~h}$ later $91 \%$ of the oocytes were still arrested at GV stage, COCs placed in FM did not maintain oocyte meiotic blockage as efficiently (Fig. 6). When EREG was added to the culture $\mathrm{CM}$ or $\mathrm{FM}$, it induced mucification and expansion of cumulus cells and oocyte meiotic resumption. The PB extrusion rate in the EREG-treated FM group $(69 \%)$ was not significantly different from the PB rate in the control group (80\%; Fig. 6). However, EREG addition to isolated COCs in CM group could not induce a similar PB rate as in controls $(59 \%)$, suggesting the presence of some regulatory factor secreted in the CM by the somatic cells.

\section{Discussion}

It has been known for a long time that $\mathrm{LH}$ action impacts on the follicle wall (granulosa and theca cells) via a series of redundant processes. It rapidly raises CAMP levels triggering cAMP-responsive genes (Laoide et al. 1993). Since the late 1980s, EGF has been reported to contribute to cumulus cell mucification and expansion and oocyte maturation (Dekel \& Sherizly 1985, Downs et al. 1988, Downs 1989). Later reports suggested the presence of locally produced EGF and/or other factors within the mammalian follicle (Das et al. 1992, Gomez et al. 1993, Fujinaga et al. 1994), and that EGF receptors may potentiate gonadotropin action in granulosa cells (Hattori et al. 1995). Recently, published data from Park et al. (2004) and Ashkenazi et al. (2005) have showed that a series of EGF-like factors (EREG, AREG and BTC) are produced by granulosa cells after the LH ovulatory stimulus. A clear upregulation of Ereg and Areg gene expressions was obtained by gonadotropin stimulation and by using an adenylate cyclase stimulator, forskolin (Sekiguchi et al. 2002, Shimada et al. 2006). Lately, it has been proven that Ereg ablation has a large impact on the onset of oocyte maturation and ovulation (Hsieh et al. 2007).

The rationale behind the use of EREG in our standard follicle culture system was to analyse its attributed effects as a mediator of the LH action during ovulatory events, and compare its effects with both a classical ovulatory stimulus (hCG/EGF) and the main member of the EGF family, EGF.
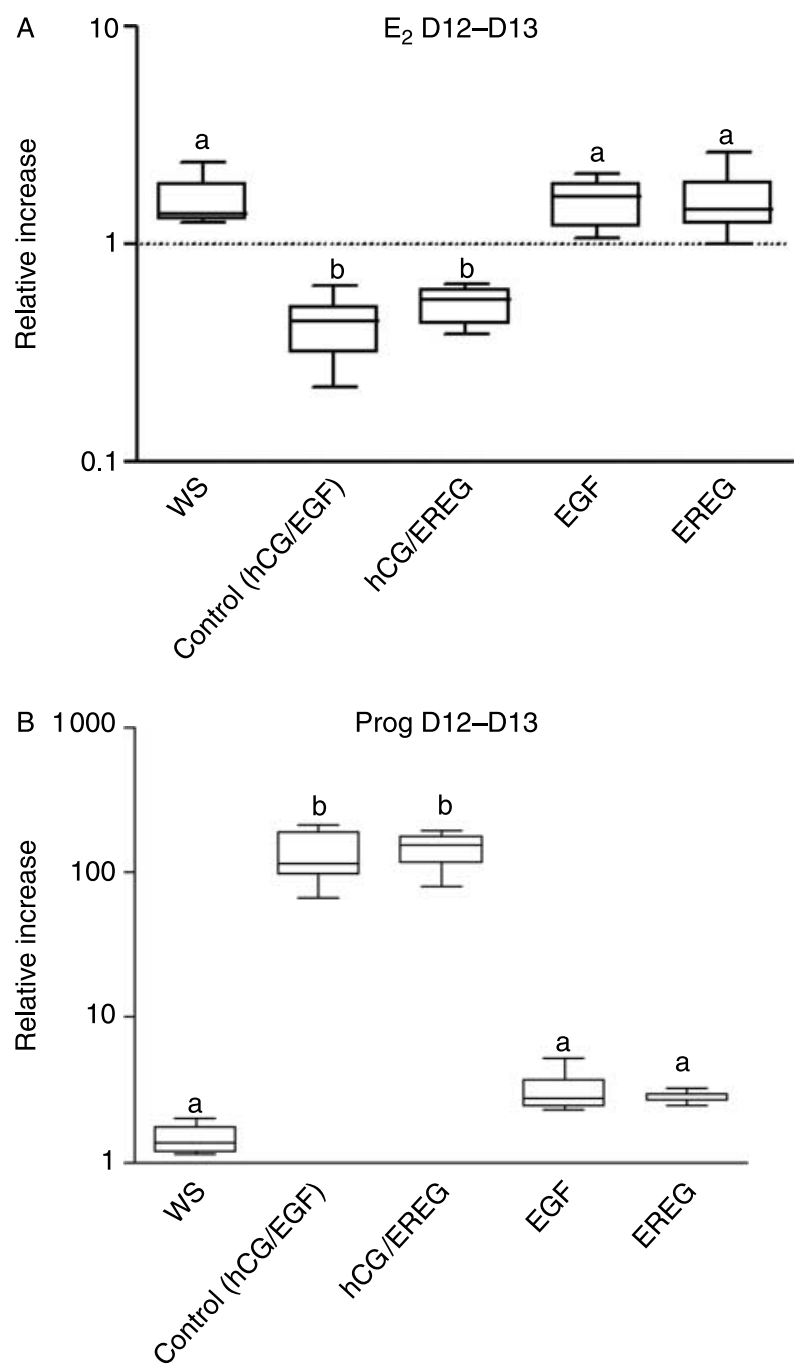

Figure 3 Steroids relative production by luteinising stimuli. (A) Relative production of oestradiol from day 12 to day 13. (B) Relative production of progesterone from day 12 to day 13. A control without stimulus (WS) was also included. Results are expressed as the relative increase in three independent replicate experiments, calculated by: day-13 value/(day-12 value $\times($ dilution factor $=0.6)$ ). Different letters indicate significant difference $(P<0.001) . n=8-9$ samples per treatment, except for the control (without stimulus) that represents four samples. One sample corresponds to pooled medium from one plate. 


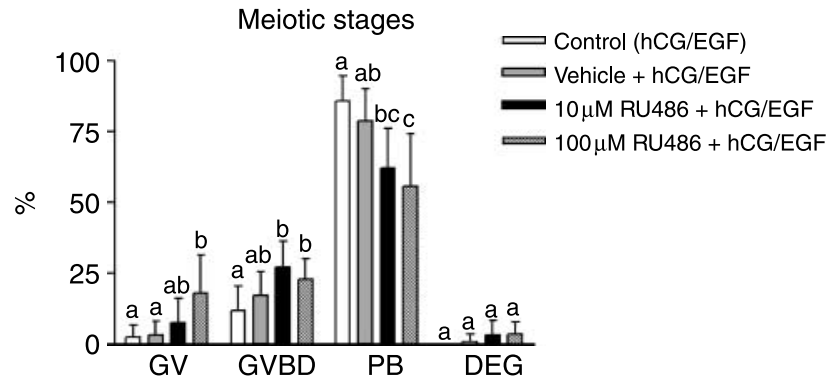

Figure 4 Meiotic stages after follicle stimulation with hCG/EGF, in the presence of the progesterone receptor-antagonist RU486. Results are expressed as mean percentage + s.D. Different letters state statistical significant difference among treatments $(P<0.05) . n=8-10$ plates per treatment obtained from three independent experiments.

First, both EGF and EREG alone induced incomplete mucification and expansion of the cumulus cells in a pre-antral follicle culture model. Compared with the control (hCG/EGF), mucification and expansion induced by EGF or EREG were more evident in peripheral cumulus cells than in the corona cells close to the oocyte. At $16 \mathrm{~h}$ after the stimulus, corona cumulus cells were still firmly attached to each other and to the oocyte. One of the genes responsible for efficient mucification/ expansion is hyaluronan synthase 2 (Has2); transcription of this gene in preovulatory follicles has been shown to be stimulated by EGF (mouse cumulus, Díaz et al. 2007b) and EREG (rat ovaries, Ashkenazi et al. 2005). Quantification of mRNA levels for Has2 revealed that both 0.65 and $65 \mathrm{nM} \mathrm{EGF} \mathrm{(100} \mathrm{times} \mathrm{more} \mathrm{EGF)} \mathrm{induce}$ only a slight increase in transcript levels in comparison with hCG/EGF stimulus. The rationale behind the use of two doses of EGF was to exclude the possibility of a reduced stimulation exerted by the lower dose as the cause for the difference in mucification induced by hCG/EGF and EGF alone. The reduced induction of Has2 transcript suggests that (under current conditions) cumulus cells of cultured follicles require the presence of $\mathrm{LH} / \mathrm{hCG}$ to fully develop the ovulatory response. $\mathrm{LH}$

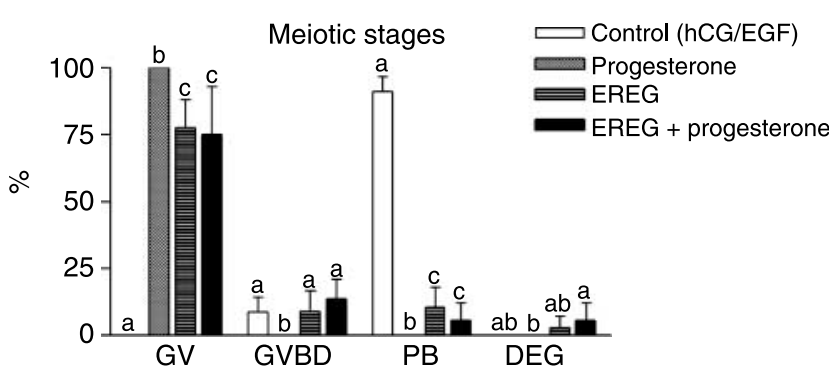

Figure 5 Meiotic stages after follicle stimulation with EREG, in the presence of progesterone addition. Results are expressed as mean percentage + S.D. of three independent experiments. Different letters state significant difference among treatments $(P<0.05) . n=12$ plates per treatment, except for the control hCG/EGF (six plates), obtained from three independent experiments.

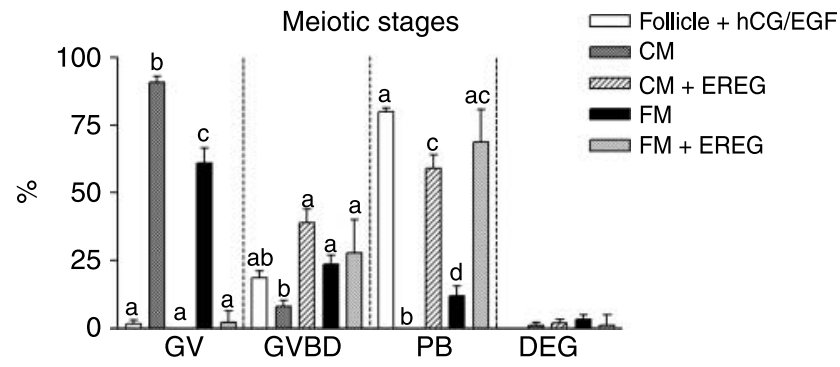

Figure 6 COCs retrieved from 12 days follicle cultures, scored $16 \mathrm{~h}$ after treatment with: conditioned medium (CM; obtained by pooling spent medium from fully grown follicles); fresh medium (FM); conditioned medium + epiregulin (CM+EREG); and fresh medium + epiregulin (FM+EREG). Follicle culture stimulated with hCG/EGF was used as control. Results are expressed as mean + s.D. of three independent experiments. Statistical significant differences are stated by different letters $(P<0.05) . n=9$ plates per treatment, except for the control 'follicle $+\mathrm{hCG} / \mathrm{EGF}^{\prime}$ ' (six plates), obtained from three independent experiments.

stimulus acts via an amplification signal, which includes the production and the paracrine/autocrine actions of EGF-like factors, progesterone and prostaglandins. The reduced response exerted by EREG might be due to a somewhat weaker amplification loop; this is supported by the reduced production of the Has2 transcript that has been shown to affect Areg and Ereg expressions (Sugiura et al. 2008).

Secondly, EREG showed a very weak effect on meiotic resumption, which was also comparable with EGF. When used in combination with hCG, EREG did repetitively induce a lower $\mathrm{PB}$ rate than hCG/EGF (only 53 vs $89 \%$ respectively; $P<0.05$ ), and $37 \%$ of the oocytes remained arrested in GVBD stage. This would suggest that in combination with hCG, EREG is less effective than EGF (Smitz et al. 1998). Moreover, it has also been shown that EGF influences the phosphorylation, ubiquitination and internalisation of connexin 43 (GJA1), the predominant functional unit of ovarian gap junctions connecting oocytes and cumulus cells (Lau et al. 1992, Leithe \& Rivedal 2004, Sela-Abramovich et al. 2005). While present, GJA1 would allow cAMP inflow from cumulus cells to the oocyte, maintaining the meiotic arrest (Sela-Abramovich et al. 2006). The lack of complete mucification in follicles treated with EGF or EREG would suggest that nonresponsive cumulus corona cells might contribute to the resistance of the complex towards the EGF-like stimulus.

Thirdly, a difference in steroids production between the control and EGF or EREG treatment was also found. The luteinisation response, i.e. progesterone production, ascribed to the LH ovulatory stimulus could not be reproduced by EGF or EREG. Although it has been shown that EGF induces progesterone secretion (Luciano et al. 1994) and inhibits $17 \beta$ HSD type 1 and aromatase in FSH-treated rat granulosa cells in culture, leading to decreased oestrogen secretion (Ghersevich et al. 1994); 
results from this experiment clearly showed that under current conditions and in comparison to hCG/EGF or hCG/EREG stimuli, EGF and EREG are poor inducers of progesterone production. Based on these results, it was hypothesised that the deficiency in oocyte meiotic maturation might be related to the failure of EGF or EREG to regulate steroids production/metabolism. Since $\mathrm{E}_{2}$ concentrations remained high and progesterone production was 100 times lower in intact follicles treated with EGF or EREG (compared with hCG/EGF or hCG/ EREG), it was decided to investigate both i) the effects of progesterone and ii) the absence of progesterone genomic activity, during oocyte nuclear maturation and follicle luteinisation. A model progesterone receptor antagonist (RU486) added to the follicle culture before ovulation induction caused indeed a dose-dependent drop in PB extrusion. However, progesterone supplementation to the EREG stimulus had no positive effect on $\mathrm{PB}$ rate, compared with the treatment with EREG alone. Moreover, progesterone supplementation by itself did not induce any morphological change in the cultured follicles.

Many reports have demonstrated that progesterone has its principal role in the process of cumulus expansion and follicle rupture (Lydon et al. 1995, Espey et al. 2000, Robker et al. 2000a, 2000b, Shimada et al. 2004).

So far, progesterone had convincingly been shown to induce oocyte meiotic maturation in X. laevis (Bagowski et al. 2001, White et al. 2005). Progesterone actions on meiotic resumption in $X$. laevis are non-genomic and RU486 antagonises the genomic effects of the progesterone receptor (Bayaa et al. 2000). To the best of our knowledge, there are only two reports showing progesterone induction of oocyte meiotic maturation in mammals. In mouse, Jamnongjit et al. (2005) showed that progesterone induced meiotic resumption in COCs and pre-ovulatory follicles. Borman et al. (2004) showed that progesterone was able to promote reinitiation of oocyte nuclear maturation after controlled ovarian stimulation in non-human primates; however, it was unable to elicit ovulation without hCG in large preovulatory follicles. Inhibition of progesterone-induced mouse oocyte meiotic maturation by mifepristone (RU486) is in agreement with the previous publication of Jamnongjit; however, our data disagree with the statement that both progesterone and EGF administration can induce oocyte maturation. The fact that RU486 did reduce oocyte nuclear maturation cannot exclusively be ascribed to a progesterone receptor antagonism; indeed, RU486 is known to be an unspecific antagonist for progesterone receptor, having also glucocorticoid receptor-antagonist activity (Teutsch \& Philibert 1994, VandeVoort et al. 2000, Svensson et al. 2001). Besides the competition for progesterone receptor, potentially, additional negative effects on oocyte and somatic cells could have played a role.
To better understand the reason for the contradictory results with literature, the next experiment was designed to reproduce one of Park's experiments in our follicle culture system (Park et al. 2004). In Park's work, COCs were retrieved from PMSG-stimulated mice. In our experiment, COCs were isolated out of in vitro cultured follicles at day 12 and transferred into a new well. Following $16 \mathrm{~h}$ of culture in CM (obtained by pooling spent medium from fully grown follicles), in absence of any of the tested stimulators, most of the COCs remained surrounded by cumulus cells and all oocytes retained their GV arrest.

When adding $100 \mathrm{nM}$ EREG, cumulus cells underwent mucification/expansion and the oocytes resumed meiosis to a high extent, comparable with hCG/EGF stimulated follicles. Ninety six percent of the oocytes reinitiated meiosis (GVBD+PB) in FM+EREG, which is even higher than $88 \%$ GVBD as was reported by Park et al. (2004). However, mucification and expansion were not as profuse as in complete follicles stimulated with hCG/EGF.

These results showed that COCs are responsive to EREG (and likely to EGF) on the condition that they are not in contact with the follicular environment (theca cells, mural cell layers or with the medium conditioned by follicle cells; Fig. 2). It is still unexplained why the EREG response cannot induce a high maturation rate in follicle-enclosed cumulus cells. We speculate that receptors for EGF family proteins might be present at different concentrations in the different follicular compartments and unequally distributed in cumulus and granulosa cells. Within cultured follicles, peripheral cumulus cells might be more responsive to EGF and/or EREG. The profuse mucification of the distal cells after stimuli and the unreactive proximal corona cumulus cells from cultured follicles suggest the existence of a radial gradient for EGF and/or EREG sensitivity. According to recently published papers, an efficient mucification and expansion of cumulus cells require also the proper EGF-induced activation of Mapk14, Mapk3/1 in these cells (Díaz et al. 2007a, 2007b).

It should also be remarked that in the work of Park, there is a preliminary priming of the mice with PMSG (FSH and LH activity). This might have sensitised cumulus cells to better respond to the EGF (or EREG) stimulus. Supporting this hypothesis is the fact that during the rat oestrous cycle, the $\mathrm{LH}$ surge on prooestrous afternoon is accompanied by an increase in ovarian EGFR concentration (St-Arnaud et al. 1983). It has also been reported that PMSG induces an enhanced expression of EGFR in the outer walls of follicles (Feng et al. 1987), and that FSH and LH (after FSH priming) dose dependently increase the expression of EGFR in rat granulosa cells (Fujinaga et al. 1994). Moreover, EGFR has been shown to be present in cumulus cells and GV oocytes from COCs collected $48 \mathrm{~h}$ 
after PMSG, as well as in oocytes following maturation (Hill et al. 1999). Localisation of EGF receptor in layers of cumulus cells from fully grown in vivo and in vitro follicles was performed. However, the immunohistochemical assays gave no positive signal, not even in COCs obtained from $48 \mathrm{~h}$ PMSG-primed mice (responsive to EGF and EGF-like factors). The possibility that the protein levels of the EGF receptor in in vitro grown COCs are lower than those from in vivo cannot yet be excluded. Quantification of mRNA for EGF receptor on D12 fully grown follicles demonstrated comparable in vitro transcript levels to in vivo (not shown).

Considering the fact that CM maintained oocyte meiotic arrest more efficiently $(P<0.001)$ than FM suggests the possibility that meiotic arrest could be sustained by a secreted inhibitory factor of follicular origin (Downs et al. 1989, Downs 1993) causing resistance to EREG or EGF stimulation.

In summary, EGF and EREG have a similar effect on oocyte maturation in this follicle culture model. Epiregulin can overcome meiotic arrest in the COC on the condition that it is first isolated from companion follicle cells and follicle fluid. EGF or EREG as the sole ovulatory stimulus to cultured follicles led to a weak response on nuclear maturation and dynamics of steroid production.

\section{Materials and Methods}

\section{Animal model}

All animals were housed and bred according to national legislation and with the consent (01-395-1) of the committee for animal experimentations of the Vrije Universiteit Brussel.

\section{Follicle culture}

Ovarian follicles from 13-day-old mice (F1 hybrids: C57BI/6j $\times \mathrm{CBA} / \mathrm{ca}$ ) were mechanically isolated and cultured as described previously (Cortvrindt \& Smitz 2002). Briefly, ovarian pre-antral follicles (with diameters between 110 and $130 \mu \mathrm{m}$ ) were dissected in Leibovitz L-15 (Invitrogen), 10\% heatinactivated foetal bovine serum (FBS), containing $100 \mathrm{IU} / \mathrm{ml}$ penicillin and $100 \mu \mathrm{g} / \mathrm{ml}$ streptomycin (Penicillin/Streptomycin-Mix, Invitrogen).

Follicles were randomly distributed (one follicle per well) into 96-well microtitre plates, half surface flat bottom (CostarElscolab, Kruibeke, Belgium) containing $75 \mu \mathrm{l} \alpha$-MEM gluta$\max$ (Invitrogen), 5\% FBS (Invitrogen), $5 \mathrm{ng} / \mathrm{ml}$ Insulin, $5 \mathrm{ug} / \mathrm{ml}$ Apo-Transferrin, $5 \mathrm{ng} / \mathrm{ml}$ sodium selenite (All from Sigma) and $10 \mathrm{mlU} / \mathrm{ml}$ r-FSH (Ares-Serono). The culture was carried out for 13 days at $37^{\circ} \mathrm{C}, 5 \% \mathrm{CO}_{2}, 100 \%$ humidity without an oil overlay. Medium refreshments were done every 4 days by replacing $30 \mu \mathrm{l}$ of spent medium by fresh one. At the set-up of culture, medium also contained $10 \mathrm{mIU} / \mathrm{ml} \mathrm{r-LH}$ (Ares-Serono). This $\mathrm{r}$-LH is subsequently washed out, as refreshment medium is not supplemented with $\mathrm{r}-\mathrm{LH}$.

\section{Follicle response to EGF and EREG}

After 12 days of culture, follicles were stimulated for oocyte meiotic reinitiation, mucification/expansion of cumulus cells and follicle luteinisation with $1.2 \mathrm{IU} / \mathrm{ml}$ recombinant hCG $+0.65 \mathrm{nM}$ recombinant EGF (control; Ares-Serono and Roche Diagnostics respectively); $1.2 \mathrm{IU} / \mathrm{ml}$ recombinant hCG +100 nM recombinant mouse EREG (R\&D systems, Minneapolis, MN, USA); and $0.65 \mathrm{nM}$ recombinant EGF or $100 \mathrm{nM}$ recombinant EREG. This concentration of EREG $(100 \mathrm{nM})$ was proven to be most effective in an in vitro condition (Park et al. 2004).

\section{Cumulus cell mucification}

On day $13,16 \mathrm{~h}$ after luteinisation, induction, mucification and expansion of cumulus cells was evaluated microscopically.

\section{Has2 expression in EGF-stimulated follicles}

Total RNA was extracted from pooled cumulus cells from five to seven fully grown follicles (on D12 and $4 \mathrm{~h}$ after stimulation with $1.2 \mathrm{IU} / \mathrm{ml}$ recombinant $\mathrm{hCG}+0.65 \mathrm{nM}$ recombinant EGF, $0.65 \mathrm{nM}$ EGF or $65 \mathrm{nM}$ EGF) using the RNeasy Micro Kit (Qiagen), according to the instructions of the manufacturer. Total RNA was reverse transcribed to cDNA using the iScript cDNA Synthesis Kit (Bio-Rad Laboratories) according to the manufacturer's instructions and using blend oligo(dT) and random hexamers. For real-time RT-PCR, quantification was performed on the LightCycler 480 (Roche Diagnostics). PCR primers for mouse Has2 were as follows: the forward primer

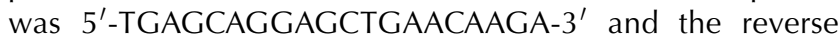
primer was 5'-GCCAACAATATAAGCAGCTGTG-3'.

The amplification reaction was carried out in a total volume of $15 \mu \mathrm{l}$ containing $2 \mu \mathrm{l} \mathrm{cDNA}, 7.5 \mu \mathrm{l} \mathrm{SYBR}$ Green PCR Master Mix $2 \times$ (Roche Diagnostics) and $0.6 \mu \mathrm{M}$ forward and reverse specific primers for Has2. The protocol for amplification cycle was as follows: $95^{\circ} \mathrm{C}$ for $10 \mathrm{~min}$ followed by 55 cycles of $95^{\circ} \mathrm{C}$ for $10 \mathrm{~s}$ and $60^{\circ} \mathrm{C}$ for $30 \mathrm{~s}$. Quantification was calculated on the basis of the standard curve generated by amplification of serial dilutions of Has2 amplicon. The analysis of the melting curve, obtained after amplification cycles, allowed checking for the specificity of the PCR product. Has2 transcript levels were normalised to $18 \mathrm{~s}$ RNA content.

\section{Oocyte meiotic maturation}

In order to assess nuclear maturation, oocytes were denuded from cumulus cells by drawing the COCs in and out of a fine bore glass pipette. Visualisation of the nuclear maturation stages was done under an inverted microscope equipped with a Hoffman modulation contrast system (Nikon, Tokyo, Japan). Oocyte nuclear maturation was scored as GV (GV was present), GVBD (GV not visible), PB (first PB was extruded) or degenerated (DEG, degenerated oocyte). Percentages of nuclear maturation were calculated per plate. Three independent experiments were performed including in total nine plates (10-12 follicles per plate) per treatment. 


\section{Assessment of steroid production by cultured follicles}

Culture medium from follicles was pooled and collected per plate (9-12 follicles) before and after the luteinisation stimulus (day 12 and day 13 respectively) and stored at $-20{ }^{\circ} \mathrm{C}$ for $E_{2}$ and progesterone measurements. All immunoassays had been validated and adapted when necessary for their use on CM.

$\mathrm{E}_{2}$ production was measured with a direct RIA from Clinical Assays (DiaSorin, Sorin Fueter, Brussels, Belgium) having a functional sensitivity of $20 \mathrm{ng} / \mathrm{l}$ and a total precision $<10 \%$ (\% coefficient of variation (CV)) between 10 and 750 ng/l. Progesterone (Prog) secretion was determined both before and after the maturation stimulus with a direct RIA from Cis-Bio (Cis Bio International, Gif-sur-Yvette Cedex, France). This assay has a functional sensitivity of $0.5 \mu \mathrm{g} / \mathrm{l}$ and a total imprecision profile $<10 \% \mathrm{CV}$ for the range from 3 to $60 \mu \mathrm{g} / \mathrm{l}$.

For all steroid measurement methods, cross-reactions with the major steroids and metabolites mentioned in the package inserts were minimal, so that the specificity was guaranteed for all methods by the manufacturers.

\section{Progesterone effects in follicle culture}

In order to analyse the effects of progesterone on oocyte meiotic maturation, two experimental set-ups were designed.

First, a known antagonist for progesterone receptor, RU486 (Sigma), was used to block progesterone action during standard stimulation with hCG/EGF. RU486 at 10 or $100 \mu \mathrm{M}$ was added to the culture wells $1 \mathrm{~h}$ before adding the stimulation medium (hCG/EGF). A vehicle control (ethanol) was also included in the analysis (maximum ethanol concentration in culture medium was $0.1 \%$ ). Nuclear maturation and mucification/expansion were scored $16 \mathrm{~h}$ after hCG/EGF stimulus in three independent experiments involving at least eight plates (9-12 follicles each) per treatment.

Second, water-soluble progesterone, cyclodextrin bound (Sigma) was combined with EREG stimulation medium (300 $\mu \mathrm{g} / \mathrm{l}$; progesterone concentration equivalent to the concentration found in follicle culture, $16 \mathrm{~h}$ after stimulation with hCG/EGF). Medium containing only progesterone was also added to the cultured follicles. Three independent experiments were performed involving in total 8-12 plates (9-12 follicles each) per treatment.

\section{Epiregulin stimulation in isolated COCs from fully grown follicles}

COCs from follicle cultures were retrieved on day 12 and transferred into new wells, containing either $\mathrm{CM}$ or $\mathrm{FM}$; in the presence or absence of 100 nM EREG. CM was obtained from the same culture as COCs by collecting and pooling medium from all plates. Nuclear maturation was scored $16 \mathrm{~h}$ poststimulus in three independent experiments. In vitro grown follicles cultured for 12 days and treated with hCG/EGF were used as a control. Results are the summary of three independent experiments involving in total nine plates (9-12 follicles each) per treatment.

\section{Statistical analysis}

Rates of nuclear maturation (GV, GVBD, PB or DEG) are expressed as percentage from the total amount of follicles on D12 of culture. Percentages of nuclear maturation stages were calculated per plate, so that each plate was considered as a unit, but representing 9-12 follicles. Depending on the experiment, 8-12 plates per experimental treatment were analysed. Before performing the statistical analysis for comparison of nuclear maturation rates, the respective percentages were converted to arcsine values.

Comparison of $E_{2}$ and progesterone production was done after calculating their relative production, by the formula: day $13 /(($ day 12$)(0,6))$; where 'day 12 ' is corrected by a dilution factor, due to medium refreshment on that day.

Significant differences among the data were calculated by one-way ANOVA with Tukey post-test using GraphPad Prism version 4.00 for Windows, GraphPad Software, San Diego, CA, USA.

\section{Declaration of interest}

The authors declare that there is no conflict of interest that could be perceived as prejudicing the impartiality of the research reported.

\section{Funding}

The authors gratefully acknowledge the Belgian Development Cooperation and the Belgian Technical Cooperation (BTC) for the grant given to Sergio Romero that allowed the completion of this work.

\section{Acknowledgements}

We thank Ann Gerard and Johan Schiettecatte for their technical assistance with immunoassays. We also thank Rita Cortvrindt for her contribution to the development of the mouse follicle culture model and initial advice.

\section{References}

Almahbobi G, Nagodavithane A \& Trounson A 1995 Effects of epidermal growth factor, transforming growth factor alpha and androstenedione on follicular growth and aromatization in culture. Human Reproduction 10 2767-2772.

Ashkenazi H, Cao X, Motola S, Popliker M, Conti M \& Tsafriri A 2005 Epidermal growth factor family members: endogenous mediators of the ovulatory response. Endocrinology 146 77-64.

Bagowski C, Myers J \& Ferrell J 2001 The classical progesterone receptor associates with p42 MAPK and is involved in phosphatidylinositol 3-kinase signaling in Xenopus oocytes. Journal of Biological Chemistry 276 37708-37714.

Bayaa M, Booth R, Sheng Y \& Liu J 2000 The classical progesterone receptor mediates Xenopus oocyte maturation through a nongenomic mechanism. PNAS 97 12607-12612.

Borman S, Chaffin C, Schwinof K, Stouffer R \& Zelinski-Wooten M 2004 Progesterone promotes oocyte maturation, but not ovulation, in nonhuman primate follicles without a gonadotrophin surge. Biology of Reproduction 71 366-373.

Cortvrindt R \& Smitz J 2002 Follicle culture in reproductive toxicology: a tool for in vitro testing of ovarian function? Human Reproduction Update 8 243-254. 
Das K, Phipps W, Hensleig H \& Tagatz G 1992 Epidermal growth factor in human follicular fluid stimulates mouse oocyte maturation in vitro. Fertility and Sterility $\mathbf{5 7}$ 895-901.

Dekel N \& Sherizly I 1985 Epidermal growth factor induces maturation of rat follicle-enclosed oocytes. Endocrinology 116 406-409.

Díaz F, Wigglesworth K \& Eppig J 2007a Oocytes are required for the preantral granulosa cell to cumulus cell transition in mice. Developmental Biology 305 300-311.

Díaz F, Wigglesworth K \& Eppig J 2007b Oocyte determines cumulus cells lineage in mouse ovarian follicles. Journal of Cell Science $\mathbf{1 2 0}$ 1330-1340.

Downs SM 1989 Specificity of epidermal growth factor action on maturation of the murine oocyte and cumulus oophorus in vitro. Biology of Reproduction 41 371-379.

Downs SM 1993 Purine control of mouse oocyte maturation: evidence that nonmetabolized hypoxanthine maintains meiotic arrest. Molecular Reproduction and Development 35 82-94.

Downs SM, Daniel SA \& Eppig JJ 1988 Induction of maturation in cumulus cell-enclosed mouse oocytes by follicle-stimulating hormone and epidermal growth factor: evidence for a positive stimulus of somatic cell origin. Journal of Experimental Zoology 245 86-96.

Downs SM, Daniel SA, Bornslaeger EA, Hoppe PC \& Eppig JJ 1989 Maintenance of meiotic arrest in mouse oocytes by purines: modulation of cAMP levels and cAMP phosphodiesterases activity. Gamete Research 23 323-334.

Eppig J 1994 Further reflections on culture systems for the growth of oocytes in vitro. Human Reproduction 9 974-976.

Espey L, Yoshioka S, Russell D, Robker R, Fujii S \& Richards J 2000 Ovarian expression of a disintegrin and metalloproteinase with thrombospondin motifs during ovulation in the gonadotropin-primed immature rat. Biology of Reproduction 62 1090-1095.

Feng P, Knecht M \& Catt K 1987 Hormonal control of epidermal growth factor receptors by gonadotropins during granulosa cell differentiation. Endocrinology 120 1121-1126.

Fujinaga H, Yamoto M, Shikone T \& Nakano R 1994 FSH and LH up-regulate epidermal growth factor receptors in rat granulosa cells. Journal of Endocrinology 140 171-177.

Ghersevich S, Poutanen M, Tapanainen J \& Vihko R 1994 Hormonal regulation of rat $17 \beta$-hydroxysteroid dehydrogenase type 1 in cultured rat granulosa cells: effects of recombinant follicle-stimulating hormone, estrogens, androgens and epidermal growth factor. Endocrinology 135 1963-1971.

Gomez E, Tarin J \& Pellicer A 1993 Oocyte maturation in humans: the role of gonadotropins and growth factors. Fertility and Sterility 60 40-46.

Hattori MA, Yoshino E, Shinohara Y, Horiuchi R \& Kojima I 1995 A novel action of epidermal growth factor in rat granulosa cells: its potentiation of gonadotrophin action. Journal of Molecular Endocrinology 15 283-291.

Hill J, Hammar K, Smith P \& Gross D 1999 Stage-dependent effects of epidermal growth factor on $\mathrm{Ca}^{2+}$ efflux in mouse oocytes. Molecular Reproduction and Development 53 244-253.

Hsieh M, Lee D, Panigone S, Horner K, Chen R, Theologis A, Lee D, Threadgill D \& Conti M 2007 Luteinizing hormone-dependent activation of the epidermal growth factor network is essential for ovulation. Molecular and Cellular Biology 27 1914-1924.

Jamnongjit M, Gill A \& Hammes S 2005 Epidermal growth factor receptor signaling is required for normal ovarian steroidogenesis and oocyte maturation. PNAS 102 16257-16262.

Laoide B, Foulkes N, Schlotter F \& Sassone-Corsi P 1993 The functional versatility of CREM is determined by its modular structure. EMBO Journal 12 1179-1191.

Lau A, Kanemitsu M, Kurata W, Danesh S \& Boynton A 1992 Epidermal growth factor disrupts gap-junctional communication and induces phosphorylation of connexin 43 on serine. Molecular Biology of the Cell 3 865-874.

Leithe E \& Rivedal E 2004 Epidermal growth factor regulates ubiquitination, internalization and proteosome-dependent degradation of connexin 43. Journal of Cell Science 117 1211-1220.

Li R, Norma J, Armstrong D \& Gilchrist R 2000 Oocyte-secreted factor(s) determine functional differences between bovine mural granulosa cells and cumulus cells. Biology of Reproduction 63 839-845.
Luciano A, Pappalardo A, Ray C \& Peluso J 1994 Epidermal growth factor inhibits large granulosa cell apoptosis by stimulating progesterone synthesis and regulating the distribution of intracellular free calcium. Biology of Reproduction 51 646-654.

Lydon J, De Mayo F, Funk C, Mani S, Hughes A, Montgomery C, Shyamala G, Conneely O \& O'Malley B 1995 Mice lacking progesterone receptor exhibit pleiotropic reproductive abnormalities. Genes and Development $92266-2278$.

Park J, Su YQ, Ariga M, Law E, Jin S \& Conti M 2004 EGF-like growth factors as mediators of LH action in the ovulatory follicle. Science 303 682-684.

Procházka R, Kalab P \& Nagyova E 2003 Epidermal growth factor-receptor tyrosine kinase activity regulates expansion of porcine oocyte-cumulus cell complexes in vitro. Biology of Reproduction 68 797-803.

Robker R, Russell D, Espey L, Lydon J, O'Malley B \& Richards J 2000a Progesterone-regulated genes in the ovulation process: ADAMTS-1 and cathepsin L proteases. PNAS 97 4689-4694.

Robker R, Russell D, Yoshioka S, Sharma C, Lydon J, O’Malley B, Espey L \& Richards J 2000b Ovulation: a multi-gene step process. Steroids $\mathbf{6 5}$ 559-570.

Sadler S \& Maller J 1981 Progesterone inhibits adenylate cyclase in Xenopus oocytes. Journal of Biological Chemistry 256 6368-6373.

Sekiguchi T, Mizutani T, Yamada K, Yazawa T, Kawata H, Yoshino M, Kajitani T, Kameda T, Minegishi T \& Miyamoto K 2002 Transcriptional regulation of the epiregulin gene in the rat ovary. Endocrinology 143 4718-4729.

Sekiguchi T, Mizutani T, Yamada K, Kajitani T, Yazawa T \& Yoshino M 2004 Expression of epiregulin and amphiregulin in the rat ovary. Journal of Molecular Endocrinology 33 281-291.

Sela-Abramovich S, Chorev E, Galiani D \& Dekel N 2005 Mitogenactivated protein kinase mediates luteinizing hormone-induced breakdown of communication and oocyte maturation in rat ovarían follicles. Endocrinology 146 1236-1244.

Sela-Abramovich S, Edry I, Galiani D, Nevo N \& Dekel N 2006 Disruption of gap junctional communication within the ovarian follicle induces oocyte maturation. Endocrinology 147 2280-2286.

Shimada M, Nishibori M, Yamashita Y, Ito J, Mori T \& Richards J 2004 Down-regulated expression of a disintegrin and metalloproteinase with thrombospondin-like repeats- 1 by progesterone receptor antagonist is associated with impaired expansion of porcine cumulus-oocyte complexes. Endocrinology 145 4603-4614.

Shimada M, Hernandez-Gonzalez I, Gonzalez-Robayna I \& Richards J 2006 Paracrine and autocrine regulation of epidermal growth factor-like factors in cumulus oocyte complexes and granulosa cells: key roles for prostaglandin synthase 2 and progesterone receptor. Molecular Endocrinology 20 1352-1365.

Smitz J, Cortvrindt R \& Hu Y 1998 Epidermal growth factor combined with recombinant human chorionic gonadotrophin improves meiotic progression in mouse follicle-enclosed oocyte culture. Human Reproduction 13 664-669.

St-Arnaud R, Walker P, Kelly P \& Labrie F 1983 Rat ovarian epidermal growth factor receptors: characterization and hormonal regulation. Molecular and Cellular Endocrinology 31 43-52.

Sugiura K, Su YQ \& Eppig J 2008 Targeted suppression of Has2 mRNA in mouse cumulus cell-oocyte complexes by adenovirus-mediated shorthairpin RNA expression. Molecular Reproduction and Development 76 537-547.

Svensson E, Markstrom E, Shao R, Andersson M \& Billig H 2001 Progesterone receptor antagonists Org31710 and RU486 increase apoptosis in human periovulatory granulosa cells. Fertility and Sterility 76 1225-1231.

Teutsch G \& Philibert D 1994 History and perspectives of antiprogestins from the chemist's point of view. Human Reproduction 9 12-31.

VandeVoort C, Overstreet J, Lasley B \& Stewart D 2000 Effects of progesterone receptor blockers on human granulosa-luteal cell culture secretion of progesterone, estradiol, and relaxin. Biology of Reproduction 62 200-205.

White S, Jamnongjit M, Gill A, Lutz L \& Hammes S 2005 Specific modulation of nongenomic androgen signaling in the ovary. Steroids $70352-360$.

Received 15 December 2008

First decision 27 January 2009

Accepted 25 March 2009 